\title{
Early Predictors of Refractory Epilepsy in Oran, Algeria: A Case-Control Study
}

\author{
Amina Chentouf ${ }^{*}$, Aicha Dahdouh ${ }^{2}$, Souad Ghomari $^{2}$, Mohand Laid Oubaich ${ }^{2}$, Malika Chaouch $^{2}$ \\ ${ }^{1}$ Department of Neurology, University Hospital of Oran, Algeria \\ ${ }^{2}$ Department of Psychiatry, University Hospital of Oran, Algeria \\ *Corresponding author: Dr. Amina Chentouf, Department of Neurology, University Hospital of Oran, Algeria,
}

E-mail: amina.chentouf@yahoo.com

\begin{abstract}
Purpose: The goal of this retrospective study is to identify early predictors of intractable epilepsy.

Methods: This case-control study conducted from January 2007 to December 2012 included 106 patients with drug-resistant epilepsy and 212 controls with well-controlled epilepsy.Univariate and multivariate analysis of predictive factors of refractoriness were performed using logistic regression.

Results: In the final model, four factors significantly associated with intractable epilepsy were identified: aetiology $(p=0.001)$, high initial seizure frequency $\left(p<10^{-4}\right)$, status epilepticus $(\mathrm{p}=0.002)$, and initial myoclonic seizures $\left(\mathrm{p}<10^{-4}\right)$.

Conclusion: Our findings suggest that the risk of developing drug resistant epilepsy could be predicted at an early stage of the disease by some clinical features. This could help the clinicians to make the best therapy decisions and improve patient's quality of life.
\end{abstract}

Received Date: February 24, 2016

Accepted Date: April 04, 2016

Published Date: April 08, 2016

Citation: Chentouf, A., et al. Early

Predictors of Refractory Epilepsy in Oran, Algeria: A Case-Control Study. (2016) Int J Neurol Brain Disord 3(1): 18- 22.

DOI: $10.15436 / 2377-1348.16 .030$

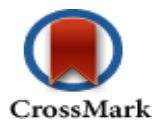

\section{Introduction}

Epilepsy is a common neurological disease characterized by recurrent and unprovoked seizures. According to data from WHO, there is more than 50 million people with epilepsy worldwide ${ }^{[1]}$. In $2 / 3$ of cases, seizures can be well controlled by antiepileptic drugs (AEDs), but in the remaining third, seizures still un-controlled ${ }^{[2,3]}$. Patients in this latter group are defined as having intractable epilepsy and are at increased risk of injury and death due to poorly controlled seizures. They also are subject to multiple trials of AEDs, often at high doses that result in adverse effects. Furthermore, they have higher rates of cognitive, physical and psychiatric comorbidities; tend to be socially isolated; face social stigma; and have poorer quality of life than those with non-intractable epilepsy ${ }^{[4,5]}$. Early identification of drug resistant epilepsy (DRE) is essential to avoid further futile therapies that could be harmful, to optimize long-term outcomes, and to decrease the burden of care.

Although several studies have investigated the predictors of medical intractability, the results were highly variable. Differences in sampling methods, inclusion criteria and particularly in DRE definitions might explain the discrepant results ${ }^{[6-10]}$.

In Algeria, the magnitude of drug resistant epilepsy (DRE) is unknown. Indeed, very few epidemiological studies on epilepsy have been published ${ }^{[1]}$ and there is no data available on predictors of refractory epilepsy. Early identification of these patients would be essential in a developing country such as Algeria, where neurologists are facing challenges in both medical and surgical management of DRE.

\section{Materials and Methods}

This retrospective case-control study was carried-out at the Department of Neurology in Oran, Algeria from January 2007 to December 2012, in consecutive age matched patients who attended our epilepsy unit. The study included patients from 3 to 75 years of age. All were diagnosed with epilepsy by the same epileptologist (AC).

We excluded patients whose seizures were uncontrolled due to poor treatment adherence or subtherapeutic serum drug levels.

Cases with intractable epilepsy were consecutively recruited. Controls consisted of consecutive age matched patients 
attending our epilepsy unit, who had no seizures during the last six months. Both cases and controls were evaluated regularly every three months.

\section{Definitions}

Epilepsy was defined as a predisposition to unprovoked seizures. For each patient, epileptic syndrome and seizures were defined according to the International League against Epilepsy (ILAE) Commission on Classification and Terminology 20052009 Report $^{[12]}$.

DRE was defined as the failure of adequate trials of two tolerated, appropriately chosen and used antiepileptic drug (AED) schedules (whether as mono-therapies or in combination) to achieve sustained seizure freedom ${ }^{[13]}$. An AED trial was considered a failure if seizures persisted at the maximally tolerated dose. We defined controlled epilepsy as the absence of seizures for at least six months.

Status epilepticus was defined according to ILAE as any seizure lasting at least 30 minutes or repeated seizures over a period of 30 minutes or more, without recovery of consciousness ${ }^{[14]}$. A family history of epilepsy was defined as unprovoked seizures occurring in first-degree relatives. Neurodevelopmental delay was diagnosed based on clinical assessment completed by a neuropsychological evaluation. Neuroimaging was classified as normal or abnormal.

\section{Data collection}

Both of the epileptic groups were questioned on their medical history, and the clinical features of seizures were noted. These included: gender, perinatal history, history of febrile/neonatal seizures, age at onset of seizures, initial seizure type, and initial seizure frequency before treatment, outcome of the first AED trial, history of inaugural status epilepticus, neuro developmental status, severe head trauma and family history of seizure disorders. According to patient's history, clinical features, electroencephalography (EEG) records and brain imaging findings, the aetiology was classified as genetic, structural/metabolic, or unknown. The appropriate antiepileptic drug was prescribed taking into account seizures type, side effects, and interaction profiles of the available drugs.

All patients enrolled in this study provided their written informed consent.

\section{Statistical analysis}

Demographic details, clinical characteristics and other relevant data were analysed using statistical package SPSS (version 21.0 for Mac OS X). The association of each factor to the dependent variable was calculated from $2 \times 2$ tables, using a $\mathrm{X}^{2}$ test of association, and a p-value of $<0.05$ was considered significant. A univariate comparison between controls and cases was done for each potential predictor to calculate Odds Ratio (OR) and 95\% Confidence Interval (CI). Finally, variables significant at the $5 \%$ nominal level were considered for multivariate analysis by logistic regression stepwise.

\section{Results}

\section{Patient profiles}

A total of 303 individuals including 106 cases (with DRE epilepsy) and 212 controls (with well controlled epilepsy) participated in the study. The mean age was 33,8 \pm 14 years, ranging from 3 to 75 years. In both case and control patients, there was a slight male predominance.

\section{Clinical features}

A comparison between cases and controls regarding clinical characteristics revealed several statistically significant differences (Table 1). Most controls (90.1\%) began their seizures after age two years, while $21 \%$ of cases had a seizure onset before the age of two years. Generalized seizures were more frequent in controls than in cases $\left(\mathrm{p}<10^{-4}\right)$. Epileptic syndromes were classified as structural/metabolic in more than third of cases, whereas in controls, there was a clear predominance of genetic epilepsies. $85 \%$ of controls were on monotherapy and around $90 \%$ of cases were on more than one AED.

Table 1: Comparison of clinical features between cases and controls.

\begin{tabular}{|c|c|c|c|}
\hline Clinical features & $\begin{array}{l}\text { Cases } \\
(n=106)\end{array}$ & $\begin{array}{l}\text { Controls } \\
(n=212)\end{array}$ & P-Value \\
\hline \multicolumn{4}{|l|}{ Age at onset } \\
\hline $\begin{array}{l}<2 \text { years } \\
>2 \text { years }\end{array}$ & $\begin{array}{l}24(20.8 \%) \\
84(79.2 \%)\end{array}$ & $\begin{array}{c}21(9.9 \%) \\
191(90.1 \%)\end{array}$ & 0.008 \\
\hline \multicolumn{4}{|l|}{ Gender } \\
\hline $\begin{array}{l}\text { Male } \\
\text { Female }\end{array}$ & $\begin{array}{l}61(57.5 \%) \\
45(42.5 \%)\end{array}$ & $\begin{array}{l}111(52.4 \%) \\
101(47.6 \%)\end{array}$ & 0.380 \\
\hline \multicolumn{4}{|l|}{ Initial seizure type } \\
\hline $\begin{array}{l}\text { Generalized } \\
\text { Focal } \\
\text { Generalized and focal }\end{array}$ & $\begin{array}{l}42(42.9 \%) \\
49(50 \%) \\
7(7.1 \%)\end{array}$ & $\begin{array}{l}145(70 \%) \\
60(29 \%) \\
2(1 \%)\end{array}$ & 0.000 \\
\hline \multicolumn{4}{|l|}{ Aetiology } \\
\hline $\begin{array}{l}\text { Genetic } \\
\text { Structural/ Metabolic } \\
\text { Unknown }\end{array}$ & $\begin{array}{l}34(32.1 \%) \\
40(37.7 \%) \\
32(30.2 \%)\end{array}$ & $\begin{array}{l}97(45.8 \%) \\
46(21.7 \%) \\
69(32.5 \%)\end{array}$ & 0.000 \\
\hline \multicolumn{4}{|c|}{ Current number of antiepileptic drug } \\
\hline $\begin{array}{l}0 \\
\text { Monotherapy } \\
\text { Bitherapy } \\
\text { polytherapy }\end{array}$ & $\begin{array}{l}0(0 \%) \\
12(11.3 \%) \\
79(74.5 \%) \\
15(14.2 \%)\end{array}$ & $\begin{array}{l}9(4.2 \%) \\
179(84.4 \%) \\
24(11.3 \%) \\
0(0 \%)\end{array}$ & 0.000 \\
\hline \multicolumn{4}{|c|}{ Current seizure frequency } \\
\hline $\begin{array}{l}\text { 1-4/month } \\
1-6 / \text { week } \\
>1 / \text { day }\end{array}$ & $\begin{array}{l}43(40.6 \%) \\
49(46.2 \%) \\
14(13.2 \%) \\
\end{array}$ & & \\
\hline
\end{tabular}

\section{Univariate analysis}

In univariate analysis, age at onset, initial myoclonic seizures, seizure frequency before treatment, aetiology, history of neonatal seizures, history of status epilepticus, neuro-developmental delay and neurological abnormalities, were found to be significantly associated with DRE (Table 2). Those factors were entered into multiple logistic regression models, with probability for entry of the variables fixed at 0.05 and that for removal at 0.10 . 
Table 2: Univariate analysis

\begin{tabular}{|l|l|l|l|}
\hline Variables with $\mathbf{p}<\mathbf{2 0 \%}$ & OR & \multicolumn{1}{|l|}{ CI95\% } & P-Value \\
\hline Gender & 1 & $\begin{array}{l}\mid \\
{[0.51-1.30]}\end{array}$ & NS \\
\hline $\begin{array}{l}\text { Female } \\
\text { Male }\end{array}$ & 0.81 & \multicolumn{2}{|l|}{} \\
\hline Age at onset & 1 & - & 0.009 \\
\hline $\begin{array}{l}>2 \text { years } \\
<2 \text { years }\end{array}$ & 2,38 & {$[1.24-4.57]$} & \\
\hline
\end{tabular}

Seizure frequency before treatment

\begin{tabular}{l|l|l|l|}
\hline$<1 /$ month & 1 & - & 0.000 \\
$>1 /$ month & 2.73 & {$[1.83-3.63]$} & \\
\hline
\end{tabular}

Initial myoclonic seizures

\begin{tabular}{|l|l|l|l|}
\hline No & 1 & - & 0.000 \\
Yes & 3.78 & {$[1.81-7.90]$} & \\
\hline
\end{tabular}

\section{Aetiology}

\begin{tabular}{l|l|l|l|} 
Genetic & 1 & - & 0.017 \\
Unknown & 1.36 & {$[0.76-2.45]$} & \\
Structural/Metabolic & 2.29 & {$[1.29-4.05]$} & \\
\hline
\end{tabular}

\section{Initial status epilepticus}

\begin{tabular}{l|l|l|l} 
No & 1 & - & 0.000 \\
Yes & 5.42 & {$[2.61-11.26]$} & \\
\hline
\end{tabular}

\begin{tabular}{|c|l|l|l|}
\hline \multicolumn{5}{|l|}{ Family history of epilepsy } \\
\hline No & 1 & - & NS \\
Yes & 1,02 & {$[0.58-1.80]$} & \\
\hline
\end{tabular}

History of febrile seizures

\begin{tabular}{|l|l|l|l|} 
No & 1 & - & NS \\
Yes & 1.91 & {$[0.99-3.66]$} & \\
\hline
\end{tabular}

\section{Neonatal seizures}

\begin{tabular}{l|l|l|l} 
No & 1 & - & 0.048 \\
Yes & 5.30 & {$[1.01-9.59]$} & \\
\hline
\end{tabular}

\begin{tabular}{|l|l|l|l|}
\hline Neurologic impairment \\
\hline No & 1 & - & 0.000 \\
Yes & 4.99 & {$[2.25-11.05]$} & \\
\hline
\end{tabular}

Neurodevelopmental delay

\begin{tabular}{|l|l|l|l|}
\hline No & 1 & - & 0.004 \\
Yes & 2.66 & {$[1.37-5.17]$} & \\
\hline
\end{tabular}

\section{Failure of first AED}

\begin{tabular}{l|l|l|l} 
No & 1 & - & 0.000 \\
Yes & 21.89 & {$[11.99-39.97]$} & \\
\hline
\end{tabular}

\section{Multiple regression analysis}

As failure of adequate AED trials is incorporated in the definition of intractability, this variable is inextricably linked to intractable epilepsy and can no longer be considered as a prognostic factor. Furthermore, we found multi-collinearity between several variables such as aetiology, focal seizures, neurologic impairment and brain imaging abnormalities; so we decided not to enter the last three variables in the initial model. We also examined interactions between variables, such as age at onset and aetiology.

In the final multivariate model by stepwise logistic regression, high initial seizure frequency $\left(\mathrm{p}<10^{-4}\right)$, initial myoclonic seizures $\left(p<10^{-4}\right)$, a previous history of status epilepticus $(p=0.002)$, and aetiology $(p=0.001)$ emerged as strong independent prognostic factors of intractability in patients with epilepsy (Table 3).

Table 3: Multivariate analysis

\begin{tabular}{|c|c|c|c|}
\hline Variables with $\mathrm{p}<5 \%$ & OR a & CI 95\% & P-Value \\
\hline \multicolumn{4}{|l|}{ Initial seizure frequency } \\
\hline $\begin{array}{l}<1 / \text { month } \\
>1 / \text { month }\end{array}$ & $\begin{array}{l}1 \\
2.58 \\
\end{array}$ & [1.68-3.48] & 0.000 \\
\hline \multicolumn{4}{|l|}{ Initial status epilepticus } \\
\hline $\begin{array}{l}\text { No } \\
\text { Yes }\end{array}$ & $\begin{array}{l}1 \\
3.94\end{array}$ & $\begin{array}{l}- \\
{[1.66-9.36]}\end{array}$ & 0.002 \\
\hline \multicolumn{4}{|l|}{ Aetiology } \\
\hline $\begin{array}{l}\text { Genetic } \\
\text { Unknown } \\
\text { Structural/Metabolic }\end{array}$ & $\begin{array}{l}1 \\
2.91 \\
3.75\end{array}$ & $\begin{array}{l}- \\
{[1.38-6.16]} \\
{[1.80-7.85]}\end{array}$ & 0.001 \\
\hline \multicolumn{4}{|l|}{ Initial myoclonic seizures } \\
\hline $\begin{array}{l}\text { No } \\
\text { Yes }\end{array}$ & $\begin{array}{l}1 \\
8.33\end{array}$ & [3.27-21.21] & 0.000 \\
\hline
\end{tabular}

\section{Discussion}

Determining the prognosis of patients with epilepsy is a challenging task. The risk assessment of a patient can be useful in adapting the therapeutic strategy.

Refractory patients have a higher risk of premature death, trauma, psychosocial difficulties, and reduced quality of life ${ }^{[15]}$. These patients are generally treated with multiple AEDs, which in combination can lead to cognitive and behavioural disorders. Knowledge of prognostic factors at an early therapeutic stage of epilepsy could facilitate patient management.

Previous studies have reported a slight predominance of epilepsy in males than in females ${ }^{[16]}$. The exact cause of this male predominance is not known. However, gender was not a predictor of drug resistance in the present study. This result is in agreement with the findings of Kwan and Brodie ${ }^{[17]}$.

The first factor strongly correlated in the literature with the risk of developing refractoriness is the aetiology of epilepsy. Our study showed that the aetiology of epilepsy is an important predictor of treatment response. This is in agreement with findings by Berg et al who reported intractable seizures in $34.6 \%$ of children with symptomatic/cryptogenic and $2.7 \%$ with idiopathic generalized childhood epilepsy. In their prospective evaluation of 613 patients, a symptomatic aetiology was significantly frequent in the group with DRE ${ }^{[18]}$. Furthermore, several large cohort studies have been performed on the prediction of seizure remission, among which the UK National General Practice Study of Epilepsy ${ }^{[19]}$ and the Dutch Study of Epilepsy in Childhood $^{[20]}$. These identified prognostic factors such as idiopathic aetiology, related to long lasting seizure remission as the opposite of intractability. In a previous report aiming to document the clinical characteristics and inheritance pattern of genetic epilepsy in Algerian families, seizure control was achieved in 21 patients $(52.5 \%)$ using mono or polytherapy. Twenty-eight (70\%) were seizure-free for 3 months and two (5\%) have been weaned for 10 years $^{[21]}$. These results might suggest that genetic aetiology is predictive of better seizure control.

In the present study, the high seizures frequency before initiation of the first AED was shown to be a predictive factor 
of refractory epilepsy. This is in line with the results of Chawla et al. Who observed that $76 \%$ of cases vs $22 \%$ of controls had one or more seizures per day $(\mathrm{P}<0.001)^{[22]}$. In the sample of Tae-sung and Holmes, daily seizures were reported in $50.7 \%$ of cases and $25.6 \%$ of controls $(\mathrm{p}<0.001)^{[23]}$. In their multivariate analysis, Huang et al. reported a high risk of refractoriness (OR: 6.54, CI: 3.13-13.7) in patients who have experienced more than ten seizures before treatment ${ }^{[24]}$. The high initial seizure frequency could cause brain injuries leading to intractability.

Previous studies have shown that myoclonic seizures were predictive of drug resistance ${ }^{[22,25]}$ while others have found no relationship between DRE and seizure type ${ }^{[26]}$. In our study, initial myoclonic seizures were significantly associated with intractability $\left(\mathrm{p}<10^{-4}\right)$. Indeed, most epilepsies with myoclonic seizures such as juvenile myoclonic epilepsy, progressive myoclonic epilepsy and severe myoclonic epilepsy in infancy are drug-resistant or drug dependent.

Initial status epilepticus was an important factor for predicting development of DRE, which was in agreement with several studies ${ }^{[23,27]}$. However, some studies did not confirm this association $^{[28]}$. Nevertheless, we cannot conclude whether status epilepticus history is a predictor of drug resistance or the consequence of poor seizure control. Further prospective studies may provide answers to this question.

A significant proportion of available studies observed a higher risk of DRE in patients whose disease has appeared at a young age ${ }^{[18,29,30]}$. In our study, this association was observed in univariate analysis, however, without statistical significance in multivariate analysis.

History of neonatal seizures was also correlated with DRE but only in univariable analysis ${ }^{[6,8,22,31]}$. Similarly, in our sample, we observed a significant tendency towards a higher risk of refractory epilepsy in this situation, but the association was not significant in multivariable analysis.

Developmental delay was observed in $20.8 \%$ of cases vs. $9 \%$ of controls, but significant association was obtained only in univariate analysis. This is in line with results of several studies $^{[3,9,22]}$.

We have not found any predictive value for family history of epilepsy in first-degree relatives. Studies aiming to assess the association between family history and intractability failed to reach statistical significance of this association ${ }^{[3]}$.

This could be explained by the fact that genetic epilepsies are probably of better prognosis than symptomatic epilepsies.

The incidence of febrile seizures (FS) in the general population is 3 to $4 \%$. In our study, FS were found in $19 \%$ of cases vs. $10 \%$ of controls. Despite this result, FS were not predictive of unfavourable outcome. Some authors have even concluded that the history of FS was a protective factor against intractability ${ }^{[18]}$.

The present study has several limitations: it was conducted in an epilepsy unit, where patients with refractory epilepsy are often referred for reassessment, so the study population was not representative of the population concerned. In addition, although we collected data prospectively, the study could be subject to recall bias. We believe that additional prospective population-based studies, considering also new predictors such as pharmacological, genetic, neurobiological, and immunological factors, are warranted. Such studies could facilitate patient management and stimulate the development of more effective therapeutic strategies, reducing the medico-social and economic burden of intractable epilepsy.

In conclusion, our findings suggest that some clinical features can predict intractability in patients with epilepsy. Early identification of these patients allows their transfer to specialized centres where a neurosurgical treatment should be considered.

\section{Conflicts of interest}

The authors declare that there is no conflict of interest regarding the publication of this manuscript.

\section{References}

1. World Health Organization (WHO). "Epilepsy”. (2014) WHO Factsheet: 999.

2. Kwan, P., Sander, J.W. The natural history of epilepsy: an epidemiological view. (2004) J Neurol Neurosurg Psychiatry 75(10): 1376-1381.

3. Sillanpaa, M., Remission of Seizures and Predictors of Intractability in Long-term follow- up. (1993) Epilepsia 34(5): 930936.

4. Tellez-Zenteno, J.F., Ronquillo, L.H., Wiebe, S., Sudden unexpected death in epilepsy: evidence-based analysis of incidence and risk factors. (2005) Epilepsy Res 65(1-2): 101-115.

5. Tomson, T., Beghi, E., Sundqvist, A., et al. Medical risks in epilepsy: a review with focus on physical injuries, mortality, traffic accidents and their prevention. (2004) Epilepsy Res 60(1): 1-16.

6. Berg, A.T., Levy, S.R., Novotny, E.J., et al. Predictors of intractable epilepsy in childhood: a case-control study. (1996) Epilepsia 37(1): 24-30.

7. Kwan, P., Brodie, M.J., Early identification of refractory epilepsy. (2000) N Engl J Med 342(5): 314-319.

8. Kwong, K.L., Sung, W.Y., Wong, S.N., et al. Early predictors of medical intractability in childhood epilepsy. (2003) Pediatr Neurol 29(1): 46-52.

9. Gururaj, A., Sztriha, L., Hertecant, J., et al. Clinical predictors of intractable childhood epilepsy. (2006) J Psychosom Res 61(3): 343-347.

10. Singhvi, J.P., Sawhney, I.M., Lal, V., et al. Profile of intractable epilepsy in a tertiary referral center. (2000) Neurol India 48(4): 351-356.

11. Chentouf, A., Talhi, R., Dahdouh, A., et al. Consanguinity and epilepsy in Oran, Algeria : A case-control study. (2015a) Epilepsy Res 111: 10-17.

12. Berg, A.T., Berkovic, S.F., Brodie, M.J., et al. Revised terminology and concepts for organization of seizures and epilepsies: report of the ILAE Commission on Classification and Terminology, 2005-2009. (2010) Epilepsia 51(4): 676-685.

13. Kwan, P., Arzimanoglou, A., Berg, A.T., et al. Definition of drug resistant epilepsy: consensus proposal by the ad hoc Task Force of the ILAE Commission on Therapeutic Strategies. (2010) Epilepsia 51(6): 1069-1077.

14. Commission on Epidemiology and Prognosis of the International League Against Epilepsy. Guidelines for epidemiological studies on epilepsy. (1993) Epilepsia 34(4): 592-596.

15. Hao, X.T., Wong, I.S., Kwan, P., Interrater reliability of the international consensus definition of drug-resistant epilepsy: a pilot study. (2011) Epilepsy Behav 22 (2): 388-390. 
16. Hauser, E., Freilinger, M., Seidl, R., et al. Prognosis of Childhood Epilepsy in newly referred Patients. (1996) J of Child Neurol 11(3): 201-204.

17. Kwan, P., Brodie, M.J., Clinical trials of antiepileptic medications in newly diagnosed patients with epilepsy. (2003) Neurology 60 (11 Suppl 4): S2-12.

18. Berg, A.T., Shinnar, S., Levy, S.R., et al. Early development of intractable epilepsy in children: a prospective study. (2001) Neurology 56(11): 1445-1452.

19. Cockerell, O.C., Johnson, A.L., Sander, J.W., Shorvon., et al. Prognosis of epilepsy: a review and further analysis of the first nine years of the British National General Practice Study of Epilepsy, a prospective population-based study. (1997) Epilepsia 38 (1): 31-46.

20. Geerts, A., Arts., W.F., Stroink, H., et al. Course and outcome of childhood epilepsy: a 15-year follow-up of the Dutch Study of Epilepsy in Childhood. (2010) Epilepsia 51(7): 1189-1197.

21. Chentouf, A., Dahdouh, A., Guipponi, M., et al. Familial epilepsy in Algeria: Clinical features and inheritance profiles. (2015b) Seizure.31: 12-18.

22. Chawla, S., Aneja, S., Kashyap, R., et al. Etiology and clinical predictors of intractable epilepsy. (2002) Pediatr Neurol 27(3): 186-191.

23. Tae-Sung, Ko., Holmes, G.L., EEG and clinical predictors of medically intractable childhood epilepsy. (1999) Clin Neurophysiol 110(7): 1245-1251.
24. Huang, L., Li, S., He, D., et al. A predictive risk model for medical intractability in epilepsy. (2014) Epilepsy Behav 37:282-286.

25. Eriksson, K.J., Koivikko, M.J., Prevalence, classification, and severity of epilepsy and epileptic syndromes in children. (1997) Epilepsia 38(12): 1275-1282.

26. Camfield, C., Camfield, P., Gordon, K., et al. Outcome of childhood epilepsy: A population-based study with a simple predictive scoring system for those treated with medication. (1993) The Journal of Pediatrics 122(6): 861-868.

27. Ohtsuka, Y., Yoshinaga, H., Kobayashi, K., et al. Predictors and underlying causes of medically intractable localization-related epilepsy in childhood. (2001) Pediatr Neurol 24(3): 209213.

28. Akhondian, J., Heydarian, F., Jafari, S.A., Predictive factors of pediatric intractable seizures. (2006) Arch Iran Med 9(3): 236-239.

29. Casetta, I., Granieri, E., Monetti, V.C., et al. Early predictors of intractability in childhood epilepsy: a community-based case-control study in Copparo, Italy. (1999) Acta Neurol Scand 99(6): 329-333.

30. Voll, A., Hernández-Ronquillo, L., Buckley, S., et al. Predicting drug resistance in adult patients with generalized epilepsy: A case-control study. (2015) Epilepsy Behav 53: 126-130.

31. Ohtsuka,Y., Yoshinaga, H., Kobayashi, K. Refractory childhood epilepsy and factors related to refractoriness. (2000) Epilepsia 41 Suppl 9: 14-17.
Online ISSN: $2377-1348$

Journal Title: International Journal Neurology and Brain Disorders Journal Short Name: Int J Neurol Brain Disord
Ommega Online Publishers

E-mail: neurology@ommegaonline.com

Website: www.ommegaonline.org 